\title{
Financial Assets Return Volatility Modeling with Using Dynamics of Describing the Mechanism for Transforming the Return Volatility
}

\author{
Nagapetyan A.R. \\ School of Economy and Management \\ Far Eastern Federal university \\ Vladivostok, Russia \\ nagapetyan_ar@fefu.ru
}

\begin{abstract}
The author suggests approaches to modeling volatility of returns of financial assets, different from the existing higher level of accuracy when out-of-sample prediction (with the formal proof on the basis of procedure - the Model Confidence Set) by taking into account the dynamics of diversification of market potential, able to describe the transformation mechanism of clustering of volatility of returns on micro-level clustering of volatility of returns on the macro level, the example of the Russian financial market. Comparison of different approaches to modeling diveraification potential based on the model families MEWMA, OGARCH, DCC and realized covariation it was found that the best quality of forecasting volatility of financial assets yield in most cases is provided by using the DCC model to calculate the index of diversification potential. This is true for stocks, stock indices and random financial portfolios. It is better to calculate diversification potential based on the OGARCH model to predict the volatility of the profitability of Markovitzefficient financial portfolios. The results obtained can be used by private investors and financial institutions to predict the volatility of financial asset returns. Financial regulators can use the diversification potential index as an indicator of macroeconomic risks in general.
\end{abstract}

Keywords-micro/macro level volatility clustering; diversification potential; EMH; volatility forecast; MEWMA; OGARCH; DCC; HAR-RV.

\section{INTRODUCTION}

In modern financial markets, one of the most destructive phenomena is the transformation of clustering of yield volatility at the micro level into clustering of yield volatility at the macro level [1]. The main reason is the ability of this factor to influence the simultaneous growth of risk indicators of almost all financial instruments in individual sectors of the economy and the financial market as a whole, which in turn can become a prerequisite for the emergence of various scales financial crises. Modern approaches to modeling and forecasting volatility are largely based on the use of the clustering volatility phenomenon, but in most cases they do not answer the question why it occurs. We believe that a possible step towards the study of the volatility clustering phenomenon causes, in turn, influence the dynamics of the volatility of the underlying can be the introduction of the diversification potential concept in a given set of assets describing how the extent of available diversification opportunities in the relevant market and the relative importance of the general macroeconomic conditions of the market generally functioning or in a particular sector compared to the private investment separately considered assets, this, in turn, will be revealed on the basis of the respective assets pairwise correlation coefficients dynamics. In periods of time when the dynamics of pairwise correlation coefficients between assets will tend to unite, the possibility of diversification will decrease, which we believe should lead to an increase in volatility at the macro level for a certain period, which in turn will see a cluster of high volatility values both at the macro level and at the level of separately considered assets. If there is demonstrated a significant effect of index investment diversification market potential for volatile stocks, stock indexes and financial portfolios, it will be a significant step in the study of both practical and theoretical issues related to the modeling of volatility as a basic parameter in risk management, and at the micro level individual investors, financial institutions, and macro financial regulators.

The aim of the study is to model the volatility of stocks, stock indices, financial portfolios returns, taking into account the dynamics of the market diversification potential

The provisions to be defended are the following results, which contain elements of novelty.

1. Formulated the concept of diversification potential in a given set of assets as factors that significantly affect the volatility of stock returns, stock indices, financial portfolios, and are crucial in the transformation mechanism of individual assets return volatility clustering in the clustering volatility of returns on the macro level and reflect the diversity of their investment characteristics in the perception of investors.

2. Tools for calculation and modeling of the market diversification potential index are developed.

3. The presence of a significant influence of the market diversification potential index on the volatility of financial assets is demonstrated. 
First of all, it is necessary to transform the yield matrix (4) [9].

4. The model of forecasting volatility of profitability of stocks, stock indices, financial portfolios, taking into account the influence of the market diversification potential dynamics and allowing to significantly improve the predictive quality of existing models.

\section{RESEARCH METHODOLOGY}

\section{A. Research problem}

The model of generalized autoregressive conditional heteroskedasticity (GARCH) is considered to be the most applied models in practice [2,3]. Another common approach is the har-RV family of realized volatility models (formulas 1 and 2 , respectively) $[4,5,6]$.

$$
\sigma_{t}^{2}=\omega+\alpha_{1} u_{t-1}^{2}+\ldots+\alpha_{p} u_{t-p}^{2}+\beta_{1} \sigma_{t-1}^{2}+\ldots+\beta_{q} \sigma_{t-q}^{2}(1)
$$

where, $\omega=\gamma V_{1}, V_{0}$ is the constant characterizing, the value of the long-term variance; $\sigma_{t}^{2}$ the square of volatility (variance) of the market indicator on the $\mathrm{n}$ th day; $u_{t-1}^{2}$ the square of the last relative change of the market indicator.

$$
\sigma_{\mathrm{t}+1 \mathrm{~d}}^{[\mathrm{dd})}=\mathrm{c}+\beta^{(\mathrm{d})} \mathrm{R} V_{\mathrm{t}}^{(\mathrm{d})}+\beta^{[\mathrm{w})} \mathrm{R} V_{\mathrm{t}}^{[\mathrm{w})}+\beta^{[\mathrm{m})} \mathrm{R} V_{\mathrm{t}}^{(\mathrm{m})}+\varepsilon_{\mathrm{t}+1}
$$

where $\sigma_{t+1 d}^{[d]}$ - estimate volatility prediction for one day, $\mathrm{RV}_{\mathrm{t}}^{[\mathrm{dd})}$ - estimate of realized volatility calculated by the formula (19), $w=5, m=22, \mathrm{RV}_{\mathrm{t}}^{[n)}=\left(R V_{\mathrm{t}}+\cdots+R V_{\mathrm{t}-\mathrm{n}+1}\right) / n, \varepsilon_{\mathrm{t}+1}-$ error of the model, subject to the law of "white noise".

A. Aganin's research demonstrates the superiority of the har-RV family of models over others (including the GARCH family) in predicting realized volatility to date. In view of this, it is with this family that it will be considered as a basis for comparison with the proposed models [7].

One of the simplest approaches to modeling multidimensional volatility is the use of a multidimensional model, exponentially weighted moving average MEWMA (3) [8].

$$
\sigma_{t i j j}=\lambda \sigma_{t-1, i j}+(1-\lambda)_{y_{t-1 i j}} y_{t-1, j}, i_{s} j=1, \ldots, K
$$

where, $\sigma_{t i j j}$ - covariance between the respective assets at a point in time $\mathrm{t} ; \lambda$ - a constant whose value is in the range from 0 till $1 ; y_{t-1}-$ the value of the relative change in the yield of an asset $i$ for the previous period of time; $y_{t-1} j-$ the value of the relative change in the yield of an asset $j$ for the previous time period.

Consider an orthogonal model of generalized autoregressive conditional heteroskedasticity or OGARCH. It is proposed to transform the yield matrix into a set of portfolios, with a key characteristic that assumes uncorrelation, which allows to predict the volatility of each portfolio separately.

$$
u=L * y
$$

where, $u$ - matrix of uncorrelated portfolios; $L-$ matrix of dimension $K \times K$ consisting of eigenvectors of the correlation matrix considered $K$ assets'; $y$ - matrix of returns considered $K$ assets'.

Another approach to the construction of the covariance matrix is the model of constant conditional correlations (DCC), where the covariance matrix is calculated by the formula $(5)[10,11]$.

$$
\Sigma_{t}=D_{t} R D_{t}
$$

where, $\Sigma_{t}-$ covariance-variation matrix; $R-$ sample correlation matrix between standardized residues; $D_{t}-$ the matrix of conditional volatility.

Sample correlation matrix $R_{t}$ modeled by the formula 50 , where $Q_{t}$ in turn is determined by the equation (6).

$$
R_{t}=\left(\operatorname{diag}\left(Q_{t}\right)^{-\frac{1}{2}} Q_{t}\left(\operatorname{diag}\left(Q_{t}\right)\right)^{-1 / 2}\right.
$$

where, $R_{\mathrm{t}}-$ the matrix of conditional correlations. $Q_{\mathrm{t}}-$ symmetric, positive definite matrix (7).

$$
\begin{gathered}
Q_{t}=(1-\alpha-\beta) Q^{*}+\alpha z_{t-1} z_{t-1}^{p}+\beta Q_{t-1} \\
Q^{*}=1 / T \sum_{t=1}^{T} z_{t} z_{t}^{p}
\end{gathered}
$$

where, $Q^{*}$ - unconditional covariance matrix of standardized residues (8); $\alpha$ и $\beta$ the parameters, such that $\alpha_{s} \beta>0$ and $\alpha+\beta<1$ to provide positive definiteness and stationarity properties; $z_{t}=\varepsilon_{t} / \sigma_{t}$ standardized balances at time t.

A model of realized covariance was proposed by Andersen and coauthors in 2003. (realized quadratic covariation-RCov) (9) [12,13].

$$
R \operatorname{Cov}_{\mathrm{t}}=\sum_{\mathrm{i}=1}^{M} r_{\mathrm{t}, \mathrm{i}} r_{\mathrm{t}, \mathrm{i}}^{t}
$$

where, $r_{\mathrm{t}, \mathrm{i}}$ - vector of intraday yield values.

The algorithm of the methodology for calculating the index of assets given set diversification potential contains the following stages.

Stage 1. Definition of a set of assets, the dynamics of the diversification potential of which needs to be evaluated. It can 
be both separate branches of economy, and the markets as a whole at the national and global level.

Stage 2. Estimation of pairwise correlation coefficients dynamics between assets from the set defined at the first stage. If the data for some assets are not available, for example, intraday quotes, you can exclude them. The dynamics of pairwise correlation coefficients can be calculated on the basis of various models given in table 1. As a separate approach, we can also consider the option of averaging the results.

Stage 3. Calculation of the diversification potential index dynamics, according to formula 10, as the average value of the pairwise correlation coefficients dynamics between the assets of the considered set, estimated on the basis of appropriate models $[14,15]$.

$$
D P I_{t}=\frac{\sum_{i s j} \operatorname{con}\left[\left(\alpha_{i} \alpha_{j j}\right]_{i e}\right.}{n}
$$

where, $D P I_{t}$ - index of diversification potential of the considered set of assets at the moment of time $t$; $\operatorname{cor}\left(a_{i}, a_{j}\right)$ - correlation coefficient between assets $a_{i} u a_{j}$ at time $\mathrm{t} ; \alpha_{\mathrm{i}} \mathrm{u} \alpha_{j}$, accordingly the share of assets in the portfolio in question at the time $\mathrm{t}$ (usually 1); $\mathrm{n}$ - number of asset pairs in a given set.

Stage 4. The choice of the diversification potential index modification depending on the existing problem. If you intend to use index of diversification potential, as a factor in the modified model, predict realized volatility HAR-RV_DPI (11), it is also possible to consider various modifications of the diversification potential index and based on the procedure outof-sample forecasting with subsequent comparison of the approaches (with the conventional model of the HAR-RV (2)) based on the MCS procedure to identify the most suitable one to predict the volatility of a particular asset [16]. You can also use the statistical criteria R2, Adj.R2, RSS, MSE, RSE, AIC, BIC.

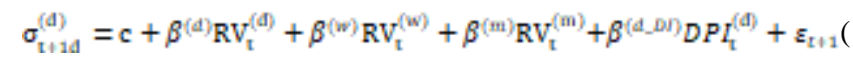

Table I provides information on financial assets, on the basis of which it is proposed to calculate the index of the market diversification potential (DPI_MICEX). 2 assets were taken from the list of financial assets with the highest index, on the basis of which the indices MICEXFNL, MICEXO\&G, MICEXPWR, MICEXTLC, MICEXM\&M are calculated (data from 29.12.2017). One more asset was taken from among the indices MICEXCGS, MICEXTRN, MICEXCHM that form the basis of calculation. Other things being equal, assets from different sub-sectors are selected.

Consideration of the relevant shares is a common practice when working with Russian market data, due to their intraday liquidity sufficient for the models used. Table II provides information on the main industry stock indices of the Moscow exchange.
TABLE I. INFORMATION ON SELECTED FINANCIAL ASSETS, ON THE BASIS OF WHICH INDUSTRY INDICES OF THE MOSCOW EXCHANGE ARE CALCULATED.

\begin{tabular}{|l|c|c|c|}
\hline № & Name & Designation & Index \\
\hline 1 & Sberbank (PAO) & SBER & MICEXFNL \\
\hline 2 & Moscow exchange (PAO) & MOEX & MICEXFNL \\
\hline 3 & LUKOIL (PAO) & LKOH & MICEXO\&G \\
\hline 4 & Gazprom (PJSC) & GAZP & MICEXO\&G \\
\hline 5 & FGC UES (PAO) & FEES & MICEXPWR \\
\hline 6 & FGC RusHydro (PAO) & HYDR & MICEXPWR \\
\hline 7 & MTS (PAO) & MTSS & MICEXTLC \\
\hline 8 & Rostelecom (PJSC) & RTKM & MICEXTLC \\
\hline 9 & Norilsk Nickel (PAO) & GMKN & MICEXM\&M \\
\hline 10 & NLMK (PJSC) & NLMK & MICEXM\&M \\
\hline 11 & Magnet (PAO) & MGNT & MICEXCGS \\
\hline 12 & Aeroflot (PAO) & AFLT & MICEXTRN \\
\hline 13 & The company (PJSC) & URKA & MICEXCHM \\
\hline
\end{tabular}

\section{TABLE II}

INFORMATION ON THE MAIN INDUSTRY STOCK INDICES OF THE MOSCOW EXCHANGE.

\begin{tabular}{|c|c|c|}
\hline № & Name & Designation \\
\hline 1 & The index of the Moscow exchange & MICEX \\
\hline 2 & Financial sector index & MICEXFNL \\
\hline 3 & Oil and gas index & MICEXOG \\
\hline 4 & The transport index & MICEXTRN \\
\hline 5 & Metals and mining index & MICEXMM \\
\hline 6 & $\begin{array}{c}\text { The index of chemical and petrochemical } \\
\text { industries }\end{array}$ & MICEXCHM \\
\hline 7 & The index of electric power industry & MICEXPWR \\
\hline 8 & The index of telecommunications & MICEXTLC \\
\hline 9 & Consumer sector index & MICEXCGS \\
\hline
\end{tabular}

Fig. 1 shows the dynamics of the diversification potential DPI_MICEX index daily values for the period from January 2014 to December 2017, calculated on the basis of formula 10, where the models of realized correlation, DCC, ARIMA, etc. were used to calculate and model daily pairwise correlation coefficients.

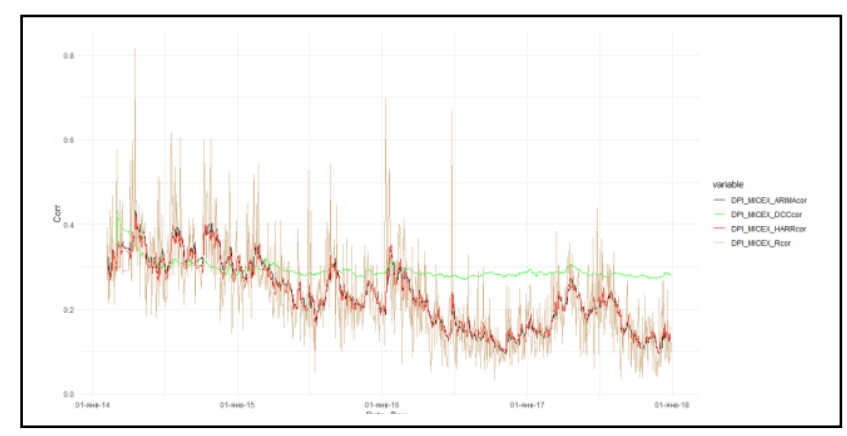

Fig.1. The dynamics of daily values DPI_MICEX

The proposed model of forecasting volatility and profitability can be used for stocks and stock indices, as well as for financial portfolios. In order to justify this, 300 portfolios were formed with random weights consisting of the assets listed in table 1. 300 financial portfolios of Markowitz companies were also formed, consisting of 8 assets, which in turn were selected from 16 assets listed in table 1 . Further, for non-repeating portfolios of 8 assets, the weights characterizing the effective set of portfolios were calculated, and the portfolio with the maximum Sharpe coefficient was selected 
from their strength. The calculations were performed in $\mathrm{R}$ using the packages and PortfolioAnalytics Portfolio.optimization. For each of the obtained portfolios, the forecast values of realized volatility were calculated in the outof-sample forecasting for one period based on the model and HAR-RV and HAR-RV_DPImean for the period from June 2017 to December 2017.

\section{RESULTS}

Let us compare the model proposed in the study (formula 11) with the existing model (2) in terms of their ability to predict the values of realized volatility outside the sample on which it was estimated. To" train " the model we will use a time interval equal to the total number of available data except for 150 days. Further, on the basis of the selected data, we estimate the parameters of the corresponding model and make a forecast for 1 period. Then we perform a new assessment of the model parameters using the same amount of data with a shift of 1 period. After the assessment, we again carry out the forecast for 1 period. After doing this procedure 150 times, we will get 150 forecast values of the corresponding model for the assets under consideration. Thus, we know the true values of the realized volatility of the financial assets in question (13 stocks, 9 stock indices, 300 random financial portfolios and 300 Markowitz-efficient financial portfolios), their forecast values obtained on the basis of the existing model HAR-RV (2) and our proposed model HAR-RV_DPI (11). Next, we use the MCS test to compare the quality of predictions.

Table III presents the results of comparing the considered har-RV and HAR-RV_DPI models (10 modifications) based on MCS over a time period of 150 days with non-selective volatility forecasting of 13 stocks (table 1), 9 stock indices (table 2), 300 random and 300 effective portfolios.

According to the simulation results, in no case did THE har-RV_DPI model (with various modifications of the models used to calculate DPI) "yield" to the har-RV model. Thus, the modification of HAR-RV_DPI_DCC was better than the har-RV model in forecasting volatility of stock indices in 8 cases out of 9 .

TABLE III. RESULTS OF FORECAST QUALITY COMPARISON USING HAR-RV AND HAR-RV_DPI MODELS (10 MODIFICATIONS) BASED ON MSC IN OUT-OF-SAMPLE FORECASTING.

\begin{tabular}{|c|c|c|c|c|}
\hline \multirow{2}{*}{$\begin{array}{c}\text { DPI } \\
\text { modification }\end{array}$} & \multicolumn{4}{|c|}{ HAR-RV_DPI rather } \\
\cline { 2 - 5 } & $\begin{array}{c}\text { Stock } \\
\text { (total } \\
\mathbf{1 3})\end{array}$ & $\begin{array}{c}\text { Stock } \\
\text { indexes } \\
\text { (total 9) }\end{array}$ & $\begin{array}{c}\text { Random } \\
\text { portfolios (a } \\
\text { total of 300) }\end{array}$ & $\begin{array}{c}\text { Markowitz- } \\
\text { efficient } \\
\text { portfolios } \\
\text { (total 300) }\end{array}$ \\
\hline MEWMA & 10 & 8 & 285 & 266 \\
\hline OGARCH & 4 & 3 & 243 & 290 \\
\hline DCC & 11 & 8 & 293 & 261 \\
\hline RV & 7 & 5 & 0 & 224 \\
\hline HARRV & 8 & 6 & 261 & 243 \\
\hline HARRVlog & 8 & 6 & 264 & 240 \\
\hline HARRVsqrt & 8 & 6 & 261 & 241 \\
\hline AARIMA & 8 & 7 & 266 & 231 \\
\hline ARIMA & 8 & 6 & 258 & 241 \\
\hline MEAN & 8 & 7 & 243 & 239 \\
\hline
\end{tabular}

In other cases, the models had the same accuracy.

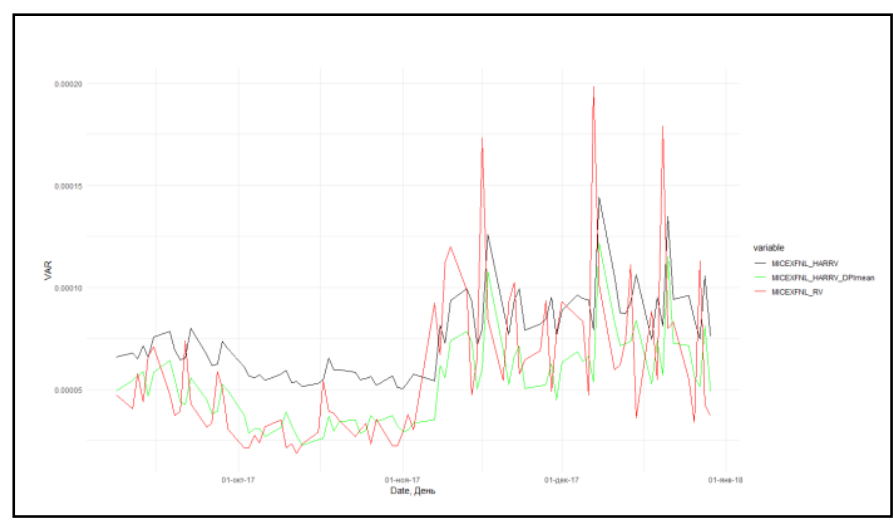

Fig. 2. Dynamics realized of MICEXFNL volatility daily values and MICEXFNL assets calculated on the basis of har-RV and HAR-RV_DPImean models for the period from January 2014 to December 2017.

Fig. 2 shows the dynamics of the MICEXFNL asset realized volatility daily values, MICEXFNL calculated on the basis of the HAR-RV model given in formula (2), without using the diversification potential index, and MICEXFNL calculated on the basis of the HAR-RV_DPImean model given in formula (11), using the diversification potential index for the period under review from January 2014 to December 2017.

\section{DisCUSSIONS}

The study shows the feasibility of modeling and calculation of the index the diversification potential of the market and its use as a proxy of the macroeconomic risks dynamics in many different models, it is necessary to expect and consider when making decisions of financial assets individual financial market participants, financial institutions and the financial controller in matters relating to the assessment and forecasting of volatility of financial assets.

The application of methodological recommendations on the use of the diversification potential for private investors index dynamics, financial corporations and institutions will allow them to make more effective decisions, in particular, when forecasting the volatility of financial assets [17].

The application of methodological recommendations on the use of the dynamics of the index of diversification potential will allow the financial regulator (CBR) to take appropriate measures in advance to prevent or reduce the negative consequences of potential crisis phenomena in the formation of prerequisites for the transformation of clustering volatility of asset returns at the micro level into clustering volatility of returns at the macro level [18].

\section{CONCLUSIONS}

The study developed a model predicting the volatility of stock returns, stock indices, financial portfolios, which differs from the existing ability to consider the impact of the market potential diversification dynamics, which, in turn, allowed to significantly improve the quality of forecasting, which was confirmed on the basis of modern procedures of financial 
[7] Aganin A. Forecast comparison of volatility models on Russian stock market. Prikladnaya ekonometrika. 2017, vol. 48, pp. 63-84.

econometrics based on venevision predict and use procedures of MCS.

In the study, it was demonstrated that the application of the proposed methodology algorithm of diversification potential indicator calculation in a given set of assets and then applying the latter in the generated models predict the volatility of return allowed to significantly improve the quality of forecasting, for example, in the case of using HARRV_DPIdcc for stocks in 11 cases out of 13, for the stock indexes for the 8 cases of 9 , random of financial portfolios, to 293 cases from 300 and effective at Markowitz financial portfolios for 261 cases out of 300. In all other cases, the models considered had the same forecast quality. To predict the volatility of the profitability of Markowitz-efficient financial portfolios, it is better to calculate the OGARCH model for DPI calculation (290 out of 300).

\section{References}

[1] Mandelbrot B. The variation of certain speculative prices. Journal of Business. 1963, 36, pp. 394-19.

[2] Engle R. Autoregressive conditional heteroscedasticity with estimates of variance of United Kingdom inflation. Econometrica. 1982, 50, pp. 987 1008 .

[3] Bollerslev T. Modeling the coherence in short-run nominal exchange rate: A multivariate generalized arch approach. Review of Economics and Statistics. 1990, 72, pp. 498-505.

[4] Corsi F. A simple long memory model of realized volatility. Journal of Financial Econometrics. 2004, 7(2), pp. 174-196.

[5] Hansen P., Lunde A. Realized variance and market microstructure noise. Journal of Business \& Economic Statistics. 2006, vol. 24, 2, pp. 17-161.

[6] Zhang L., Mykland P., Ait-Sahalia Y. A tale of two time scales: determining integrated volatility with noisy high-frequency data. Journal of the American Statistical Association. 2005, vol. 100, 472, pp. 1394 1411 .
[8] Danielson J. Financial Risk Forecasting. United Kingdom, WILEY. 2011.

[9] Alexander C, Chibumba A. Multivariate orthogonal factor GARCH. University of Sussex Discussion Papers in Mathematics. 1996.

[10] Engle R. Dynamic conditional correlation - a simple class of multivariate GARCH models.Journal of Business and Economic Statistics. 2002, 20(3), pp. 339-350.

[11] Engle R, Kroner F. Multivariate simultaneous generalized ARCH. Econometric Theory. 1995, 11, pp. 122-150.

[12] Andersen T., Bollerslev T, Diebold F., Labys P. Modeling and forecasting realized volatility. Econometrica. 2003, 71(2), pp. 579-625.

[13] Girardi G., Ergun A. Systemic Risk Measurement: Multivariate GARCH Estimation of Covar. Journal of Banking \& Finance. 2013, 37(8), pp. 3169-80.

[14] Nagapetyan A. Stock Return Correlation Simulation to Calculate the Diversification Potential Index for a Set of Assets. Theory and practice of social development. 2019, 6, pp. 54-61.

[15] Nagapetyan A. Stocks return volatility clustering in Russian market: preconditions and interpretations. Proceedings of the International Conference on Trends of Technologies and Innovations in Economic and Social Studies 2017. 2017, pp. 456-462.

[16] Hansen P., Lunde A., Nason J. The model confidence set. Econometrica. 2011, vol. 79, 2, pp. 453-497.

[17] Rubinshtein E., Saltykov M., Nagapetyan A., Diachenko Y., Brizitskaya A. Comparison of banks of China and Australia by Return on Assets and Capital. Proceedings of the International Conference on Trends of Technologies and Innovations in Economic and Social Studies 2017. 2017, pp. 563-568.

[18] Alexsandr S. Kuznetsov. Russian Professor's meeting. Russian Journal of Physical Education and Sport. 2019, 14(1), pp. 17-22. DOI: 10.14526/2070-4798-2019-14-1-18-24

[19] Mollick A., Assefa T. US stock returns and oil prices: The tale from daily data and the 2008-2009 financial crisis. Energy Economics. 2013, vol. 36 , pp. 1-18. 